\title{
Microwave-assisted conversion of ethane to ethylene
}

\author{
Siauw Ng $\cdot$ Craig Fairbridge $\cdot$ Sateesh Mutyala $\cdot$ \\ Yan Liu · Jacqueline M. R. Bélanger • \\ J. R. Jocelyn Paré
}

Received: 4 October 2012/Accepted: 28 February 2013/Published online: 4 April 2013

(c) The Author(s) 2013. This article is published with open access at Springerlink.com

\begin{abstract}
A novel microwave reactor has been constructed for the conversion of ethane to ethylene. The bench-top, pilot-scale facility is capable of conventional furnace heating and microwave-assisted heating, thus allowing direct comparative studies between the conventional industry-wide process and the novel microwaveassisted conversion process. The latter makes use of chemical substances called susceptors that are good microwave absorbers and can transfer heat energy to the surrounding environment. The ethane feed stream is thus heated to achieve thermal conversion to ethylene. Data validating the apparatus and preliminary data on the feasibility of conversion are presented.
\end{abstract}

Keywords Ethylene production - Microwave-assisted petrochemistry $\cdot$ Ethane-to-ethylene conversion .

Microwave susceptors

\section{Introduction}

As a continuation of our work in further developing technologies for novel microwave-assisted processes (MAP ${ }^{\mathrm{TM}}$ ) [1-13], we have undertaken a research program aimed at assessing the feasibility of using microwaves as a processing tool in the industrial sector. More specifically, we have an interest in assessing and validating applications for

S. Ng $\cdot$ C. Fairbridge $\cdot$ S. Mutyala $\cdot$ Y. Liu

Natural Resources Canada, CanmetENERGY, One Oil Patch

Drive, Devon, AB T9G 1A8, Canada

J. M. R. Bélanger · J. R. J. Paré ( $\square)$

Your World, 94 Newton Street, Moncton, NB E1E 3A4, Canada

e-mail: jrjpare@microwaveworldwide.com the petrochemical and petroleum sectors with the aim to reduce energy intensity as well as greenhouse gas emissions.

Ethylene production is an important industrial activity in Canada. For example, NOVA Chemicals alone-Canada's largest producer of ethylene-has a publicly reported production capacity of over 2.5 billion $\mathrm{kg} / \mathrm{year}$. The process used currently is relatively simple $[14,15]$ : ethane is fed into long tubular reactors at temperatures of roughly $850-900{ }^{\circ} \mathrm{C}$ and pressures slightly over atmospheric. Once the materials leave the reactor, they must be cooled to $450{ }^{\circ} \mathrm{C}$ within $50 \mathrm{~ms}$ to prevent further polymerization of the ethylene or its degradation into side products. Currently, no catalyst is used in the Canadian plant as Canada still has access to significant quantities of pure ethane from its natural gas production. This situation is likely to change in the near future as excess ethane boil-off is rapidly depleting, thus raising the likelihood of the need to implement chemical catalytic processes.

\section{Experimental setup}

The experimental apparatus consisted of three main sections: supply, reaction, and sampling. A simplified schematic of the overall experimental apparatus is shown in Fig. 1. The following provides a general description for each section.

\section{Supply section}

The supply section consisted of three feed lines for hydrocarbon feedstock: ethane (in this study), nitrogen, and steam. Ethane (Praxair, $99.9 \%$ pure) was fed to the reaction section from a regulated supply cylinder using a mass 
Fig. 1 Simplified schematic diagram of the overall ethylene conversion bench-top pilot plant

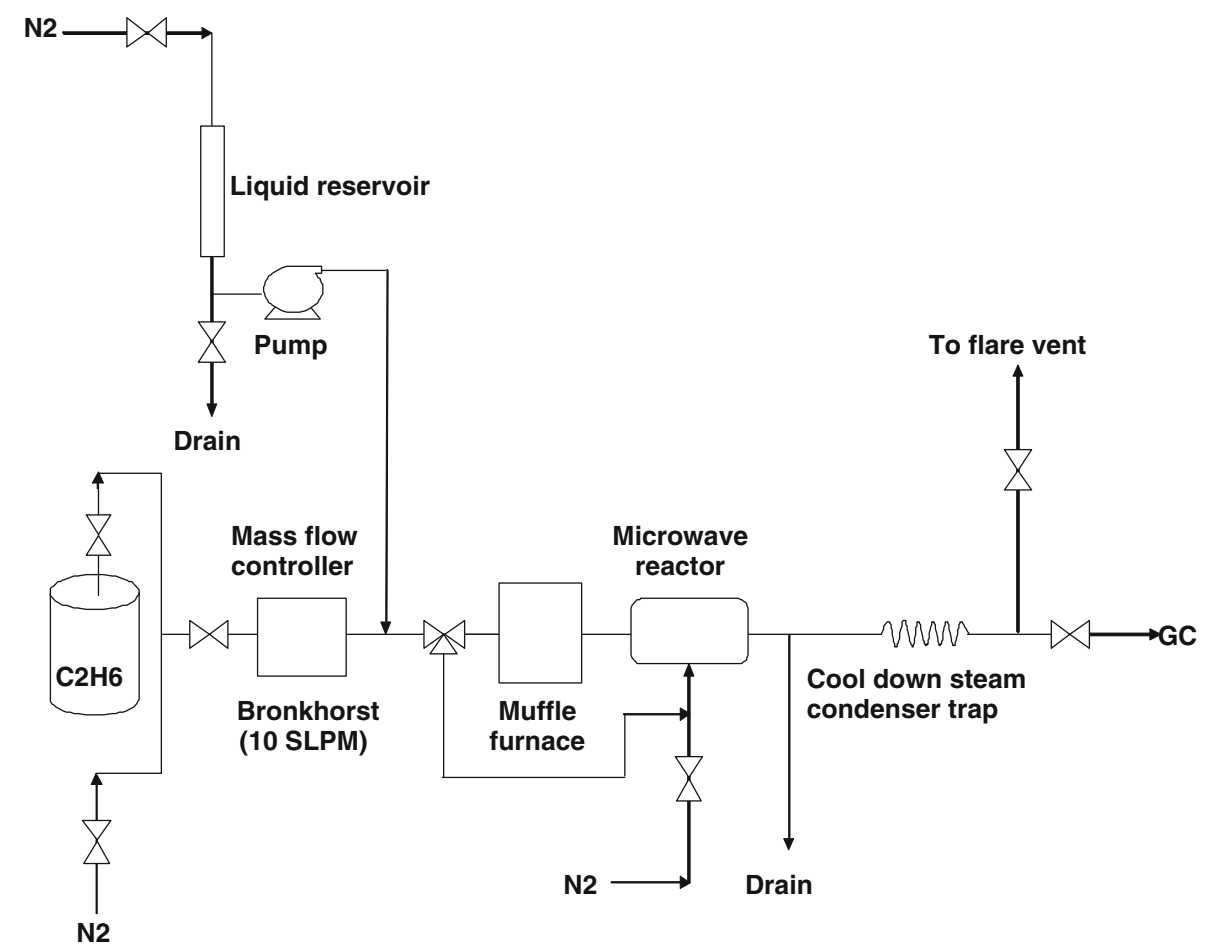

flow controller (Bronkhorst). The flow rate of ethane was set by the controller with an accuracy of \pm 0.1 standard liters per minute (SLPM). The flow rate was the volumetric flow rate corrected to a temperature of $20{ }^{\circ} \mathrm{C}$ and pressure of $101.3 \mathrm{kPa}$. When the ethane was fed to the reactor, a pressure relief valve (not shown in Fig. 1) was used to equalize the pressures upstream and downstream from the flow-regulating valve to prevent backpressure on the feedstock lines and downstream pressure fluctuations.

\section{Reaction section}

The bench-top pilot facility is capable of conventional furnace heating and microwave-assisted heating. The furnace heater section can also be used to preheat the feedstock prior to entry into the microwave reactor section if desired. The system can accommodate tubular reactors of varying diameters. Figure 2 shows the overall layout of the apparatus. The path taken by the feedstock, namely directly into the microwave reactor or via the furnace section, is controlled by a switchable multipath flow valve.

\section{Microwave reactor system}

The system has been described previously in detail from the design and modeling [16] as well as from the construction and assembly standpoints [17]. The main components of the experimental arrangement in this study are a microwave generator and a cavity (reactor system) connected via appropriate waveguides. The microwave system includes adequate protection systems to prevent any reflected power from damaging the magnetron head.

The microwave generator is a $2,450-\mathrm{MHz}, 3-\mathrm{kW}$ GMP $30 \mathrm{KSM}$ (Sairem) that can be operated at nominal power ratings ranging between 300 and 3,000 $\mathrm{W}$. The magnetron of the generator is protected by a high-flow water cooling system set at $4{ }^{\circ} \mathrm{C}$. A rectangular waveguide with a standard size of WR340 is located at the power head. It is connected to a WR430 waveguide via a waveguide transition. The latter waveguide serves as a wall to the cavity and is slotted on the side facing the cavity, allowing long uniform emission of microwaves into the cavity. Five slots centered at the middle of the wall are cut, with alternate angles at $145^{\circ}, 35^{\circ}$, $145^{\circ}, 35^{\circ}$, and $145^{\circ}$. The rectangular reactor cavity has overall dimensions of $40 \times 40 \times 30 \mathrm{~cm}$.

A three-stub impedance-matching tuner is fitted between the emission head and the slotted waveguide. The generator is equipped with emitted and reflected power measurement devices in real time. The cavity was designed for multipurpose applications. It can be operated with a single waveguide. Alternatively, it can also be operated by attaching a second slotted waveguide on the opposite face of the cavity. That second waveguide has slots cut differently so as to avoid the potential for obtaining high-field points that could lead to undesirable arcing phenomena [16]. The reactor was designed to be housed in the 
Fig. 2 Photograph of the bench-top pilot facility showing the overall layout

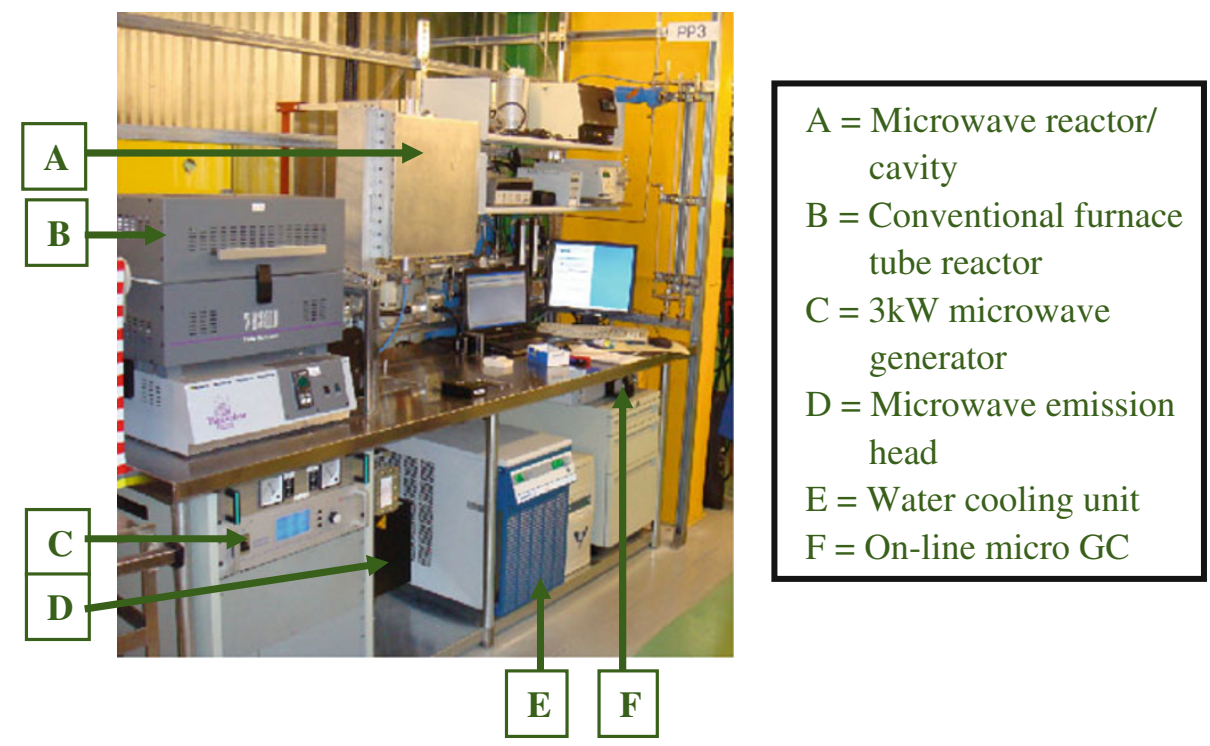

rectangular microwave cavity [17], which is most appropriate for applying microwave heating to continuous flows of fluids or to solids in granular form. Two cylindrical metal chimneys centered on the top and bottom walls of the cavity were fitted to allow the insertion of one tubular reactor. The open-ended tubular reactor passes vertically through these holes into the microwave cavity.

In this work, a quartz tube ( $2.54 \mathrm{~cm}$ or $1^{\prime \prime}$ ID) was used as reactor. The tube was packed with the susceptor to allow for the direct transfer of microwave energy onto the susceptor. Silicon carbide (SiC), a good microwave absorber as reported by Kim et al. [18], was selected as the susceptor for this work. The ethane feed flow rate was set to 0.5 SLPM. The height of the dielectric sample was set between 5 and $30 \mathrm{~cm}$. As the material in the reactor is heated, its dielectric properties change, thus causing the impedance to change with time. We used an Agilent network analyzer E5070B to insure that optimal conditions were found. The three-stub tuner was adjusted to compensate for impedance changes and a reflector plate was also used to adjust the maximum field strength in the reactor tube. Once the process steady state had been reached, the impedance-matching device no longer required much adjustment.

Temperature evolution was monitored via an optical pyrometer (Luxtron) located at the center of the packed bed. The optical pyrometer lens head operated in the range from 300 to $2,000{ }^{\circ} \mathrm{C}$ and is known not to be affected when used within electromagnetic fields.

\section{Conventional furnace reactor system}

The bench-top pilot system includes a conventional electrical muffle furnace (operable up to $1,200{ }^{\circ} \mathrm{C}$ ) that can house quartz tube reactors having diameters up to around $5 \mathrm{~cm}$. A Bench Link data recorder was used to record the temperature profiles during the reaction. Flow rates allowed for processing ethane in the range of liters per hour. The reactor muffle furnace temperature was adjusted when nitrogen gas was flowing until the system reached the desired temperature conditions before ethane was introduced. A condenser accessory was available for use when experiments were carried out using superheated steam to dilute the ethane (to reduce its partial pressure). Steam is normally present to reduce carbon deposition when working under conventional processing conditions.

Sampling section

Analysis of product gases was performed by an on-line four-channel micro gas analyzer (Agilent 3000A micro GC) located after the outlet of the reactor and after a cold trap used to remove solid particles, such as coke produced from secondary reactions, prior to entering into the micro gas chromatograph. The micro GC was calibrated with standard gases and gaseous mixtures prior to the experimental run.

\section{Results and discussion}

One of the main problems with the conventional heating process is the overheating of some zones within the reactor, which leads to coking, a process that usually results in significant losses in production and reduced energy efficiency. To mitigate this problem, the process makes use of injected superheated steam to reduce the partial vapor pressure of ethane and to "clean" the surface of the reactor, 
thus minimizing the potential for hot spots along the tubular structure. Steam may actually account for as much as $30 \%$ of the feedstock. It is believed that thermal control can be improved using microwaves because, inherently, microwaves do not exhibit thermal inertia. In fact, a large amount of the energy used in the existing process is due to the need to generate and superheat the steam. Water has a heat capacity roughly double that of ethylene and therefore accounts for a significant portion of the energy needed in that process unit. It is believed that eliminating or reducing the amount of steam required would significantly reduce the energy requirements of the process.

The technical challenges facing the novel microwavebased process are mostly associated with high-volume flow regimes. One Canada-based plant, for example, produces $135 \mathrm{Mt}$ of ethylene per hour. Despite the gigantic scale of the process, it is believed to be amenable to microwave treatment because, much like in the conventional process, the reactors required would be relatively small in diameter and, as such, do not represent a significant challenge with respect to the microwave penetration parameter. An issue that remains is that of scale-up to provide a cavity having uniform electric field quality over the necessary length, which does represent a significant technical challenge that will require innovative cavity design approaches [16-23].

One additional challenge is the introduction of novel catalysts into the reactors based on their selective microwave absorption. Energy efficiency would be increased using catalysts capable of selectively absorbing the microwaves and serving to heat the ethane flowing through the catalyst bed.

\section{Microwave-assisted process}

As a preliminary test for microwave dehydrogenation of ethane, the performance of selected dielectric materials was investigated in fixed-bed vertical reactor using pure, non-preheated, ethane. The reactor could be divided into zones 1 (gas inlet), 2 (reaction), and 3 (gas outlet) packed with quartz wool $\left(7.6 \mathrm{~cm}\right.$ or $3^{\prime \prime}$ bed, as support), $\alpha$-SiC particles (16 mesh, $5 \mathrm{~cm}$ or $2^{\prime \prime}$ bed), and quartz wool again (7.6 $\mathrm{cm}$ bed), respectively. During reaction, product gas was analyzed every $8 \mathrm{~min}$ starting at $735^{\circ} \mathrm{C}$ and terminated at $\sim 760{ }^{\circ} \mathrm{C}$ after 32 min test duration. Four sets of data were collected. Ethane conversion, ethylene selectivity, and yields of major and minor gaseous products were calculated from the micro GC data. Coke formation was noticed mainly in zone 2 , little in zone 3 , and none in zone 1. Coke was determined from the weight difference of the reactor plus $\mathrm{SiC}$ before and after the combustion, a nonspecific test for coke determination with greater error as expected. The results are given in Figs. 3, 4 and Table 1. Figure 3 demonstrates sharp increases in ethylene yield

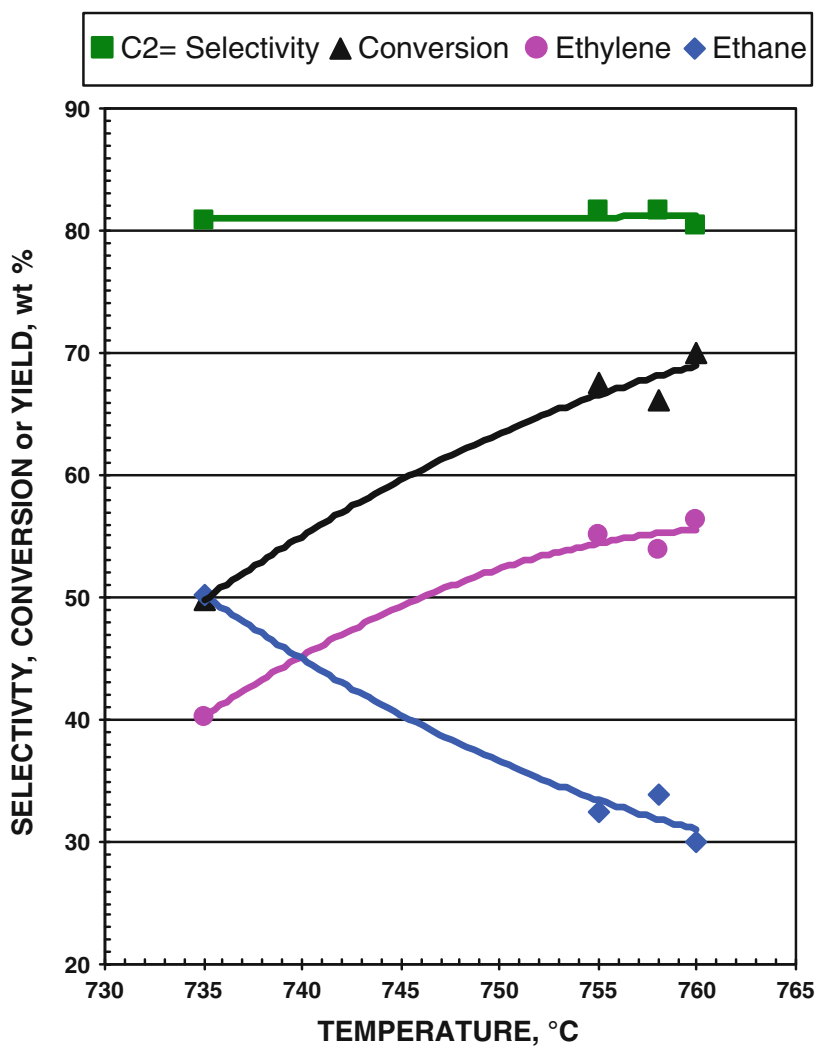

Fig. 3 Selectivity, conversion, and yields of major reaction products over a range of temperature for typical microwave-assisted processes

and conversion rendering a relatively constant selectivity over a period from 735 to $760{ }^{\circ} \mathrm{C}$.

Conventional thermal process

Conventional pyrolysis of ethane was conducted at $800 \pm 1^{\circ} \mathrm{C}$ using a horizontal quartz reactor $(2.54 \mathrm{~cm}$ or $1^{\prime \prime} \mathrm{ID} \times 30 \mathrm{~cm}$ or $12^{\prime \prime} \mathrm{L}$ ). Similarly, the reactor could be divided into zones 1 (gas inlet), 2 and 3 (gas outlet) packed with quartz wool $\left(7.6 \mathrm{~cm}\right.$ or $3^{\prime \prime}$ bed, for gas preheating), quartz particles (16 mesh, $15.2 \mathrm{~cm}$ or $6^{\prime \prime}$ bed), and quartz wool again $(7.6 \mathrm{~cm}$ bed), respectively. When reaching steady state at $800 \pm 1{ }^{\circ} \mathrm{C}$, GC data were collected for every 7-15 min over a total of $180 \mathrm{~min}$ period producing 16 sets of data. Average data are shown in Table 1. Coke formation was observed mainly in zones 2 and 3, some in zone 1 (in area close to zone 2) as demonstrated in Fig. 5, indicating that coke could also be formed in quartz wool bed if the temperature was high enough. Note that coke formation along the reactor was mostly covered by a metering tape in Fig. 5. Total coke yield was determined at the end of the test through combustion followed by $\mathrm{CO}_{2}$ absorption by ascarite (composed of $\mathrm{NaOH}$ ) forming $\mathrm{Na}_{2} \mathrm{CO}_{3}$ and $\mathrm{H}_{2} \mathrm{O}$ which was absorbed by $\mathrm{Mg}\left(\mathrm{ClO}_{4}\right)_{2}$. It 


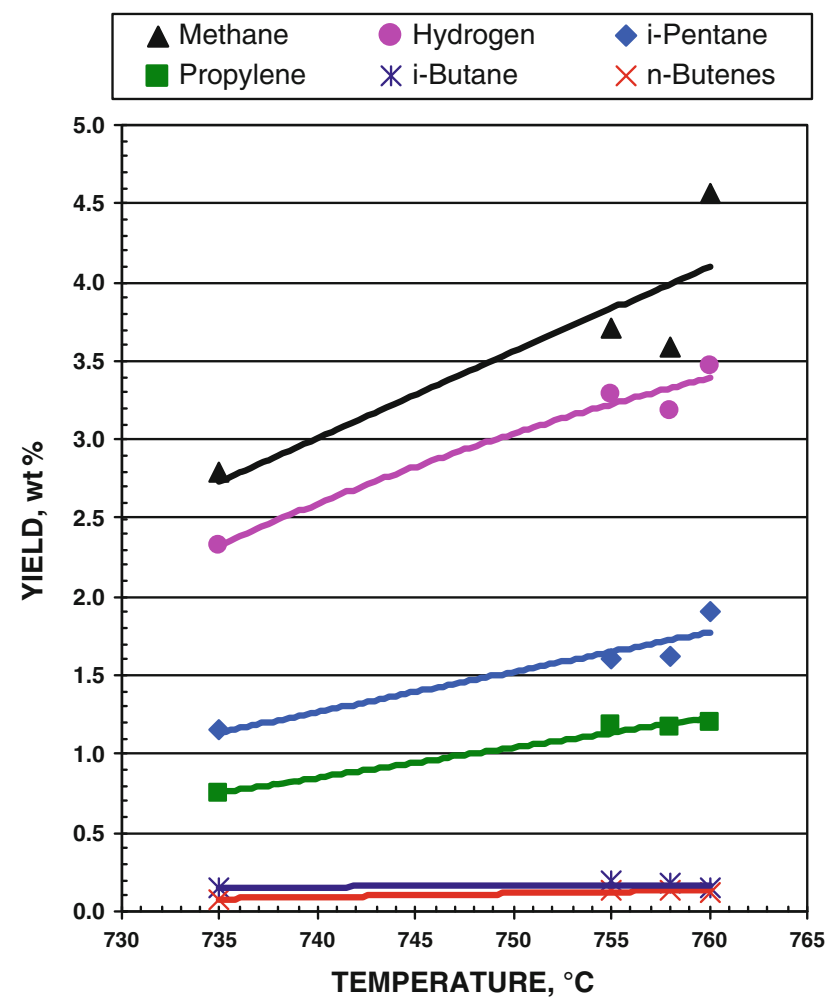

Fig. 4 Yields of minor reaction products over a range of temperature for typical microwave-assisted processes

Table 1 Comparison of conversion, selectivity, and yields between microwave-assisted and thermal cracking processes

\begin{tabular}{llll}
\hline & $\begin{array}{l}\text { Microwave- } \\
\text { assisted }\end{array}$ & $\begin{array}{l}\text { Thermal } \\
\text { cracking }\end{array}$ & $\begin{array}{l}\text { Microwave/ } \\
\text { thermal } \times \\
100(\%)\end{array}$ \\
\hline Temperature $\left({ }^{\circ} \mathrm{C}\right)$ & $757.5 \pm 5.0$ & $800 \pm 1$ & \\
Ethane flow rate (L/min) & 0.5 & 0.5 & \\
Bed packing material & SiC particles & Quartz particles & \\
Length of bed (cm) & 5 & 15.2 & \\
Test duration (min) & 24 & 164 & \\
Number of data point & 3 & 16 & 94.7 \\
Conversion (wt\%) & 67.89 & 71.71 & 99.5 \\
Ethylene selectivity $(\%)$ & 81.18 & 81.59 & \\
Yields (wt\%) & & & 94.2 \\
Ethylene & 55.10 & 58.51 & - \\
Ethane (unconverted) & 32.11 & 28.29 & 84.2 \\
Methane & 3.96 & 4.70 & 97.3 \\
Hydrogen & 3.31 & 3.41 & 70.2 \\
Iso-pentane & 1.71 & 2.44 & 68.1 \\
Propylene & 1.19 & 1.75 & 80.6 \\
Iso-butane & 0.17 & 0.21 & 39.6 \\
$n$-Butenes & 0.13 & 0.33 & - \\
Coke & 2.29 & 0.14 & 99.61 \\
Mass balance (wt\%) & 99.92 & & \\
\hline
\end{tabular}
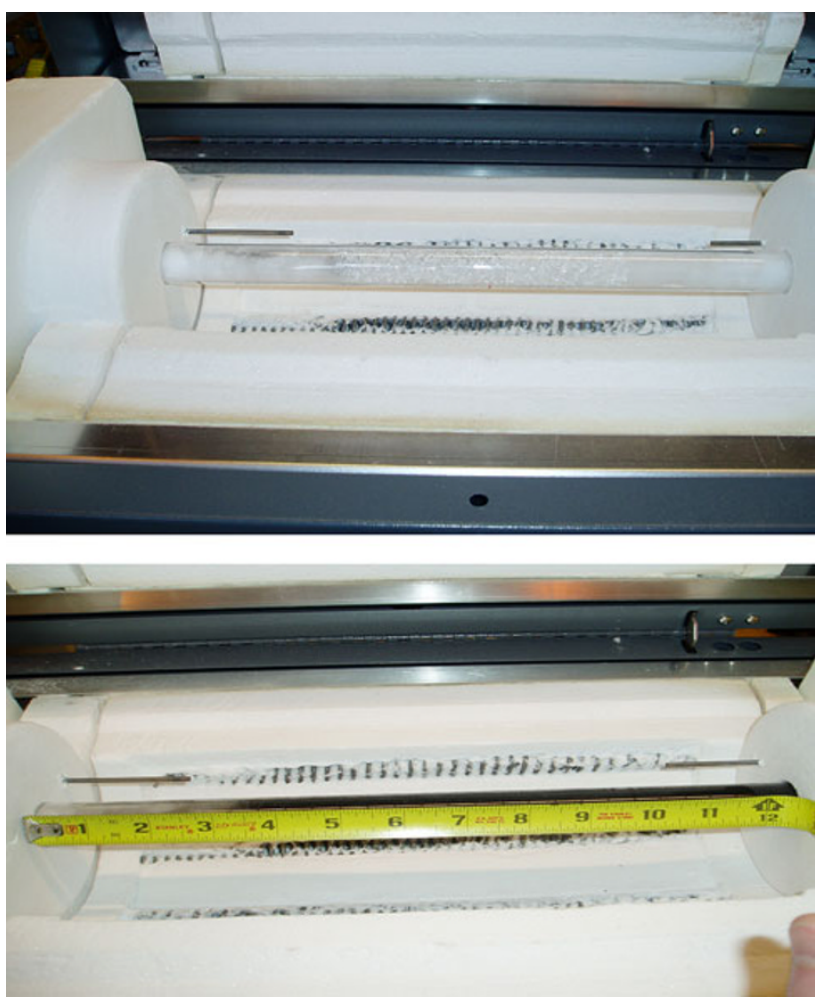

Fig. 5 Interior of the conventional electrical muffle furnace with reactor filled with quartz particles and quartz wool; top before reaction; bottom after carrying out an ethane-to-ethylene conversion process

can be seen from Table 1 that at $757.5 \pm 5.0{ }^{\circ} \mathrm{C}$, microwave results, in terms of conversion and gaseous product yields, are lower than their corresponding counterparts at $800 \pm 1{ }^{\circ} \mathrm{C}$ by conventional heating. However, the ratio of the former to the latter multiplied by 100 is, in general, greater than $70 \%$, especially for the core product (ethylene) which is over $94 \%$. Thus, with lower temperatures by $\sim 40{ }^{\circ} \mathrm{C}$ but still high ethylene yield, microwave treatment demonstrates the potential huge energy savings over conventional heating, considering the high volumes of gases to be treated.

The lower microwave results are likely due to the lower temperature of the experiment $\left(\sim 760\right.$ vs. $\left.800{ }^{\circ} \mathrm{C}\right)$, although it can also be attributable to the shorter $\mathrm{SiC}$ bed $(5 \mathrm{~cm})$ in microwave study vs. longer bed $(30 \mathrm{~cm})$ filled with quartz particles $(15.2 \mathrm{~cm})$ and quartz wool, in the conventional test. It is anticipated that ethane will undergo more cracking when passed through a longer reaction zone (longer retention time). Thus, for all practical purposes and without attempts to further optimize the process, it is believed that, when compared with conventional ethane pyrolysis, the microwave-assisted cracking will give similar conversion, ethylene yield, and other gaseous product yields at $800{ }^{\circ} \mathrm{C}$ based on the trends observed in Figs. 3 and 4. 
It is also noteworthy that the reactor outlet temperature when using the microwave reactor was only a few degrees above room temperature. This rapid self-cooling phenomenon proves to be useful in reducing or avoiding the polymerization of the products as it occurs in the commercial conventional process which requires a fast heat exchange at the outlet of the reactor.

\section{Conclusions}

A novel cavity for the microwave-assisted conversion of ethane to ethylene has been tested and validated from an operational standpoint. The results obtained in this study showed that similar ethylene yields exist between the two approaches, conventional and microwave. Furthermore, yields of components from secondary reactions are also similar in magnitude for the two processes. This suggests that the same reaction pathway is being followed in both cases.

These results are promising from a process standpoint and clearly demonstrate the feasibility of the microwaveassisted process. Further, these preliminary results warrant further work to optimize the application, specifically in terms of increased temperature and further reductions in reaction times. This experimental optimization work will also focus on increasing the electric field intensity, a parameter known to be of importance [8], by making use of a second slotted waveguide facing the one used in the present work [17].

These results would justify the development of an additional program area of designing and manufacturing novel microwave-susceptible materials that would serve as enhanced reactor components or as catalysts. The overall goal is to provide microwave-specific conditions that cannot be achieved via conventional processing, including higher process temperatures, shorter residence times, and no preheating (hence a significantly larger temperature difference between the susceptor surface and the reagent gas).

The approach is based on selective heating with the aim of further reducing energy consumption while exploring new chemical pathways. This new industrial research tool opens the door to other studies aimed at determining whether the reaction kinetics can be altered by judicious application of microwaves using complementary support and catalytic materials to reduce overall energy usage and greenhouse gas emissions.

An objective of the work was to see if maximum microwave field could be adjusted within the sample to make microwave-assisted process more energy efficient. Experimental data showed energy deposition efficiency very close to the modeling data [16].
Another objective of the work was to see if microwaveassisted ethane conversion could be energy efficient. Although no final data were obtained and further work is required to take into account all process units energy requirements, this work has demonstrated that the reaction carried out at lower temperature gave similar products without pre-heating and super-heated steam for the microwave work. The latter alone could bring energy savings of $50 \%$. This number will be reduced of course by the fact that, in a conventional process, some of the reactor heat is recuperated during the quenching step and used in other process units. Preliminary projections still show a minimum of $30 \%$ overall energy savings if large-scale feasibility is demonstrated at similar conversion rates.

Acknowledgments We are indebted toward NOVA Chemicals of Canada for technical information about industrial operational requirements. The authors would like to acknowledge support from the Government of Canada's interdepartmental Program of Energy Research and Development, PERD 1.1.3. Petroleum Conversion for Cleaner Air.

Open Access This article is distributed under the terms of the Creative Commons Attribution License which permits any use, distribution, and reproduction in any medium, provided the original author(s) and the source are credited.

\section{References}

1. Paré JRJ, Sigouin M, Lapointe J (1991) Microwave-assisted natural products extraction. U.S. Patent 5,002,784

2. Paré JRJ (1994) Microwave extraction of volatile oils and apparatus therefor. U.S. Patent 5,338,557

3. Paré JRJ (1995) Microwave-assisted generation of volatiles, of supercritical fluid, and apparatus therefor. U.S. Patent 5,337,426

4. Paré JRJ (1995) Microwave-assisted extraction from materials containing organic matter. U.S. Patent 5,458,897

5. Paré JRJ (1996) Microwave-assisted generation of volatiles, of supercritical fluid, and apparatus therefor. U.S. Patent $5,519,947$

6. Paré JRJ (1997) Microwave-assisted generation of volatiles, of supercritical fluid, and apparatus therefor. U.S. Patent 5,675,909

7. Paré JRJ (1998) Microwave-assisted generation of volatiles, of supercritical fluid, and apparatus therefor. U.S. Patent 5,732,476

8. Paré JRJ, Bélanger JMR, Punt MM (2000) Controlled energy density microwave-assisted processes. U. S. Patent 6,061,926

9. Paré JRJ, Bélanger JMR, Stafford SS (1994) Microwave-assisted process $\left(\mathrm{MAP}^{\mathrm{TM}}\right)$ : a new tool for the analytical laboratory. Tr Anal Chem 13:176-184

10. Paré JRJ, Bélanger JMR (1997) Microwave-assisted processes $\left(\mathrm{MAP}^{\mathrm{TM}}\right)$ : principles and applications. In: Paré JRJ, Bélanger JMR (eds) Instrumental methods in food analysis Chap. 10. Elsevier, Amsterdam

11. Paré JRJ, Bélanger JMR (2011) Microwave-assisted extraction. In: Pawliszyn J, Lord H (eds) Handbook of sample preparation Chap. 12. John Wiley, New York

12. Bélanger JMR, Paré JRJ, Poon O, Fairbridge C, Ng S, Mutyala S, Hawkins R (2008) Remarks on various applications of microwave energy. J Microw Power Electromagn Energy 42:24-44 
13. Mutyala S, Fairbridge C, Paré JRJ, Bélanger JMR, Ng S, Hawkins R (2010) Microwave applications to oil sands and petroleum: a review. Fuel Process Technol 91:127-135

14. Van Goethem MWM, Barendregt S, Grievink J, Moulijn JA, Verheijen PJT (2007) Ideal chemical conversion concept for the industrial production of ethene from hydrocarbons. Ind Eng Chem Res 46:4045-4062

15. Froment GF, Van de Steene BO, Van Damme P, Narayanan S, Goosens AG (1976) Thermal cracking of ethane and ethanepropane mixtures. Pilot plant versus industrial data. Ind Eng Chem Process Design Develop 15:495

16. Mutyala S, Fairbridge C, Paré JRJ, Ankam B, Bélanger JMR (2011) Design and numerical simulation of a high-efficiency microwave applicator for industrial processes. Hydrocarbon World 6(1):71-75

17. Liu Y, Fairbridge C, Paré JRJ, Ng S, Bélanger JMR, Mutyala S (2011) Optimization of microwave applicator for improved energy efficiency and homogeneity. Chimica Oggi/Chemistry Today 29(4):14-17

18. Kim DK, Cha CY, Lee WT, Kim JH (2001) Microwave dehydrogenation of ethane to ethylene. J Ind Eng Chem 7(6):363-374

19. Sutton WH (1992) Microwave processing of ceramics-an overview, microwave processing of materials iii. In: Proceedings of the symposium at materials research society, 269:3-20

20. Stevenson AF (1948) Theory of slots in rectangular waveguides. J Appl Phys 19:24-38

21. Stegen RJ (1951) Longitudinal shunt slot characteristics, Hughes Aircraft Company, Tech Memo No. 261

22. Elliott RS (1981) Antenna theory and design. Prentice-Hall, Englewood Cliffs, pp 407-414

23. Edgar RH, Osepchuk J (2001) Consumer, commercial, and industrial microwave ovens and heating systems. In: Datta AK, Anantheswaram RC (eds) Handbook of microwave technology for food applications. Marcel Dekker, New York, pp 215-277 